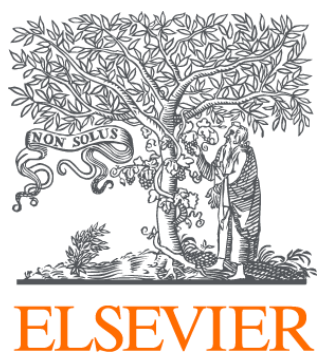

Since January 2020 Elsevier has created a COVID-19 resource centre with free information in English and Mandarin on the novel coronavirus COVID-

19. The COVID-19 resource centre is hosted on Elsevier Connect, the company's public news and information website.

Elsevier hereby grants permission to make all its COVID-19-related research that is available on the COVID-19 resource centre - including this research content - immediately available in PubMed Central and other publicly funded repositories, such as the WHO COVID database with rights for unrestricted research re-use and analyses in any form or by any means with acknowledgement of the original source. These permissions are granted for free by Elsevier for as long as the COVID-19 resource centre remains active. 


\section{Challenges in the Practice of Sexual Medicine in the Time of COVID-19 in Spain}

Jose Torremade, MD, PhD, FEBU, FECSM, and

Juan Ignacio Martínez-Salamanca, MD, PhD, FACS, FEBU, FECSM 2,3,4

At the end of December 2019, the existence of a new pneumonia of unknown causes was reported in the city of Wuhan (Hubei, China). ${ }^{1}$ Only 3 months later, the World Health Organization declared a pandemic caused by a new coronavirus (COVID-19), ${ }^{2}$ resulting in an unprecedented crisis in most of the world's health-care systems. Many countries have been overwhelmed by this pandemic and have adapted their facilities and staff in record time to fight against it. But, at the same time, many health-care services have been affected, including sexual medicine. In light of this situation, we are faced with a series of challenges to keep on offering continuity in medical care, education, and research.

\section{MEDICAL CARE}

The COVID-19 pandemic has forced health-care systems to elaborate contingency plans and to restructure their facilities to cope with the peak of coronavirus cases in the best possible conditions. In a first phase, the aim is to provide the health-care system with a greater capacity to care for coronavirus patients at the expense, in many cases, of canceling nonurgent medical activity. For this reason, most of the in-office activities have been canceled or postponed. In addition, many countries have limited their citizens' mobility, which may hinder access to nonurgent medical services. Therefore, many departments have opted for telemedicine to continue caring for their patients. Telemedicine allows for contact with patients without the need for them to visit a medical facility, thus avoiding crowds and contacts in the facilities (and therefore avoiding possible contagion between patients and professionals). Moreover, it has a lower cost and allows for a flexible follow-up adapted to the needs of the patient. ${ }^{3}$ Previous experiences with telemedicine have shown good results, ${ }^{4}$ and nowadays it has become a necessary tool to adapt to the pandemic.

Surgical activity in the field of sexual medicine has also been affected by the pandemic. Many procedures have been canceled

Received May 3, 2020. Accepted May 5, 2020.

'Hospital Universitari de Bellvitge, Urology Department, Hospitalet de Llobregat, Spain;

${ }^{2}$ Hospital Universitario Puerta de Hierro, Urology Department, Majadahonda, Spain;

${ }^{3}$ Lyx Instituto de Urología, Madrid, Spain;

${ }^{4}$ Universidad Francisco de Vitoria, Madrid, Spain

Copyright @ 2020 , International Society for Sexual Medicine. Published by Elsevier Inc. All rights reserved.

https://doi.org/10.1016/j.jsxm.2020.05.012 because of the need to adapt medical facilities to the new scenario which requires a greater number of intensive care units (ICUs) and mechanical ventilators. Many operating rooms have been converted into ICUs, and as a result, their availability has been reduced, with priority being given to emergency and oncologic surgeries which cannot be delayed. Different societies have taken a stance on the prioritization of surgeries, classifying them as low/intermediate/ high priority or emergencies. Most surgical procedures related to sexual medicine fall into the category of low/intermediate priority, so they can be postponed between 3 and 6 months. Only surgery and cryopreservation for testicular cancer are considered procedures that cannot be delayed. ${ }^{5}$ This will result in an increase in surgery waiting lists with a significant impact on the quality of life of untreated patients. Sexual medicine departments will need to adapt their surgical programs and come up with efficient models that absorb the accumulated demand efficiently and use strategies based on minimally invasive procedures. Models based on outpatient clinics also seem more necessary than ever as they reduce the contact of the patient with the hospital and therefore reduce the risk of contact between patients and professionals.

\section{MEDICAL EDUCATION}

Residency training and fellowship programs have been drastically affected. This is due, first of all, to the lack of medical personnel in many hospitals, which has forced many residents and specialists to work in special COVID-19 units. Second, the lack of medical care activity related to sexual medicine has drastically reduced the possibilities of training. For instance, a recent study carried out among Italian urology residents during the COVID-19 period found that the percentage of residents experiencing a severe reduction $(>40 \%)$ or complete suppression $(>80 \%)$ of training exposure ranged between $41.1 \%$ and $81.2 \%$ for "clinical" activities and between $44.2 \%$ and $62.1 \%$ for "surgical" activities. This reduction was even more pronounced for residents attending the final year of training. ${ }^{6}$ This has forced many departments to reinvent themselves, using new information technologies as a tool to stay in touch with the specialty.

Another COVID-19 effect that we will experience is the way we interact as a society, and therefore, congresses and scientific events will undoubtedly be affected. The annual congresses of various scientific societies and other scientific events have had to be canceled, postponed, or changed to a virtual format. Sexual medicine will need to be taught based on new online training platforms, combining training in clinical care, surgical, and 
research abilities. Virtual contact between departments will also be necessary to exchange experiences. Webinars, interactive online congresses, virtual meetings, and so on will undoubtedly become the main source of training in times of pandemic.

\section{RESEARCH}

The COVID-19 pandemic has concentrated the efforts of many scientists to learn about and treat the disease in a way never seen before in medicine. Many medical trials related to COVID19 have been produced in record time (around 1,000 studies registered at clinicaltrials.gov), which hopefully will soon provide results. ${ }^{7}$ But at the same time, many other studies that were underway have been limited or interrupted. Recruiting new patients or the clinical monitoring of those already included in these studies has become seriously hampered, so a delay in the publication of their results is to be expected. Furthermore, the economic crisis that will result from the pandemic may limit public and private resources allocated to research. That is why sexual medicine must be prepared for an environment where obtaining resources will become more competitive.

As a specialty that treats all aspects of sexual health, sexual medicine has always been strongly influenced by social changes. Beyond its health and economic impact, the COVID-19 pandemic will also bring about social changes in our society. But given that sexual medicine is a consolidated specialty and that, throughout its history, it has demonstrated its ability to adapt to new challenges, it will surely emerge stronger from this situation so that we can improve the care for our patients.

Corresponding Author: Juan Ignacio Martínez-Salamanca, MD, PhD, FACS, FEBU, Hospital Universitario Puerta de Hierro, Majadahonda, Spain. Tel: (+34) 9151349 50; Fax: (+34) 9326076 24; E-mail: jims09@icloud.com

Conflict of Interest: The authors report no conflicts of interest.

Funding: None.

\section{STATEMENT OF AUTHORSHIP}

\section{Category 1}

(a) Conception and Design

Juan Ignacio Martínez-Salamanca; Jose Torremade (b) Acquisition of Data Jose Torremade; Juan Ignacio Martínez-Salamanca

(c) Analysis and Interpretation of Data Juan Ignacio Martínez-Salamanca; Jose Torremade

\section{Category 2}

(a) Drafting the Article Jose Torremade; Juan Ignacio Martínez-Salamanca

(b) Revising It for Intellectual Content Juan Ignacio Martínez-Salamanca; Jose Torremade

\section{Category 3}

(a) Final Approval of the Completed Article Jose Torremade; Juan Ignacio Martínez-Salamanca

\section{REFERENCES}

1. WHO | Novel Coronavirus - China [Internet]. WHO. World Health Organization; [cited 2020 Apr 29]. Available at: http://www.who.int/csr/don/12-january-2020-novel-coronaviruschina/en/. Accessed January 12, 2020.

2. WHO Director-General's opening remarks at the media briefing on COVID-19 - 11 March 2020 [Internet]. [cited 2020 Apr 29]. Available at: https://www.who.int/dg/speeches/detail/whodirector-general-s-opening-remarks-at-the-media-briefing-oncovid-19-11-march-2020. Accessed March 11, 2020.

3. Hakim AA, Kellish AS, Atabek U, et al. Implications for the use of telehealth in surgical patients during the COVID-19 pandemic. Am J Surg https://doi.org/10.1016/j.amjsurg.2020.04.026. Epub ahead of print

4. Ellimoottil C, Skolarus T, Gettman M, et al. Telemedicine in Urology: State of the Art. Urology 2016;94:10-16.

5. Ribal MJ, Cornford P, Briganti A, et al. European Association of Urology Guidelines Office Rapid Reaction Group: An Organisation-wide Collaborative Effort to Adapt the European Association of Urology Guidelines Recommendations to the Coronavirus Disease 2019 Era. Eur Urol https://doi.org/10.1016/j. eururo.2020.04.056. E-pub ahead of print.

6. Amparore D, Claps F, Cacciamani GE, et al. Impact of the COVID-19 pandemic on urology residency training in Italy. Minerva Urol Nefrol https://doi.org/10.23736/S0393-2249.20. 03868-0. E-pub ahead of print.

7. Search of: COVID-19 - List Results - ClinicalTrials.gov [Internet]. [cited 2020 Apr 29]. Available at: https://clinicaltrials.gov/ct2/ results?cond=COVID-19. Accessed April 29, 2020. 